\title{
Modeling Returns and Volatility Transmission from Crude Oil Prices to Leone-US Dollar Exchange Rate in Sierra Leone: A GARCH Approach with Structural Breaks
}

\author{
Morlai Bangura*, Thomas Boima, Sandy Pessima, Isatu Kargbo \\ Staff of the Research Department, Bank of Sierra Leone, Freetown, Sierra Leone \\ Email: *molicools1971@gmail.com
}

How to cite this paper: Bangura, M., Boima, T., Pessima, S., \& Kargbo, I. (2021). Modeling Returns and Volatility Transmission from Crude Oil Prices to Leone-US Dollar Exchange Rate in Sierra Leone: A GARCH Approach with Structural Breaks. Modern Economy, 12, 555-575.

https://doi.org/10.4236/me.2021.123029

Received: February 5, 2021

Accepted: March 22, 2021

Published: March 25, 2021

Copyright $\odot 2021$ by author(s) and Scientific Research Publishing Inc. This work is licensed under the Creative Commons Attribution International License (CC BY 4.0).

http://creativecommons.org/licenses/by/4.0/

\begin{abstract}
This paper sought to shed light on the impact of shocks to global oil prices on the Leone/US Dollar exchange rate in Sierra Leone during the post war period spanning 2002M6 to 2020M5. To achieve this, the paper employed the GARCH family models with structural breaks. After establishing the existence of ARCH effects and ensuring stationarity of the data set, the paper first applied both GARCH $(1,1)$ and GARCH $(1,1)$ in Mean models to capture the symmetry effect of global oil prices increase on exchange rate. Furthermore, the paper employed exponential GARCH (EGARCH $(1,1))$ model to capture the asymmetric impact of oil price increase on the Leone/US Dollar exchange rate. Among the three models estimated, the EGARCH $(1,1)$ model was found to have the best fit as all of its mean and variance coefficients were not only found to be statistically significant but also had the least values of the model selection criteria. The empirical results suggest that an increase in oil price leads to depreciation of the exchanges rate in Sierra Leone and that exchange rate volatility exhibits persistence and autoregressive behavior. Furthermore, the paper finds evidence of asymmetry, indicating that positive shocks to crude oil prices will lead to a higher volatility in the exchange rate than negative shocks of the same magnitude. Finally, the paper finds evidence of structural breaks in the exchange series. The main policy implication from these findings is that the monetary authority should consider global oil price dynamics and the past history of exchange rate movements when formulating policy responses to exchange rate volatility in Sierra Leone.
\end{abstract}

\section{Keywords}

GARCH, Crude Oil Price, Exchange Rate 


\section{Introduction}

Since the 1980s and more so after the financial crisis of 2007-2009, the relationship between oil prices and the US dollar exchange rate has generated/received considerable attention in the theoretical and empirical literature. This interest has arisen as result of significant fluctuations in global oil prices observed in recent decades. This has motivated several theoretical and empirical research that attempts to focus on the nexus between global oil prices and the exchange rate (see Golub (1983); Krugman (1983); Bloomberg \& Harris (1995); Ghosh (2011); Aloui et al. (2013); Afees Salisu and Mobolaji (2013); Oluwatomisin et al. (2014); Jiranyakul (2015); Mishra (2016); Dauda Mohammed et al. (2019); Narayan et al. (2008); Turhan et al. (2014)). In particular, fluctuations in oil prices in recent years have placed pressure on the external account and led to exchange rate fluctuations (Bal \& Rath, 2015).

In the theoretical literature pioneered by Golub (1983) and Krugman (1983), exchange rate has been identified as the primary channel through which fluctuations in oil prices are transmitted to the real economy. This is so because, with oil priced in US dollars, shocks to oil prices may have knock-on effects on the dollar value of the currencies of both oil exporting and importing economies. In particular, these authors postulated that when oil prices rise, oil importing countries may experience exchange rate depreciation while oil exporting economies may experience an appreciation in their exchange rate and vice versa. In addition, crude oil prices have been identified to have both supply and demand side impacts on the exchange rate. The supply side impact is based on the fact that oil is a major intermediate product in the production process. Therefore, any increase in oil price would affect production negatively by increasing the factors of production of non-tradable goods and ultimately lead to an appreciation of the exchange rate. On the demand side, depreciation or devaluation of the domestic currency could increase production when a country adopts an export oriented growth strategy. Alternatively, exchange rate can indirectly affect consumer spending by contracting their disposable incomes. Thus, the spike in oil prices reduces the purchasing power of consumers, thereby reducing the demand for non-tradables. This would trigger a fall in their prices and ultimately lead to a depreciation of the domestic currency.

After the end of the civil war in 2002, there were concerns in Sierra Leone as to the response of exchange rate to fluctuations in global oil prices. Monitoring the developments in global oil prices is of importance for Sierra Leone given its high oil import bill, which over the years has averaged about 20 percent of the country's total import bill (Bank of Sierra Leone). In addition, oil is a major input in the key sectors of the economy and therefore oil price shocks may have implications for developments in the real sector. To cushion the impact of oil prices on the exchange rate, the central bank in collaboration with development partners set up a non-competitive window in the weekly foreign exchange auction in 2002 to support the private sector with foreign currency to import petro- 
leum products.

As the economy recovered and increased foreign inflows were realized, the non-competitive window for oil importers was abandoned in 2007. Consequently, importers were expected to source their forex needs from the commercial banks. However, as the economy continues to expand with increasing energy intensity in both the tradable and non-tradable sectors, the official market could not meet the increasing foreign currency needs of the oil marketing companies. Thus, oil marketing companies incurred significant outstanding foreign obligations to their suppliers. In order to addresses these challenges, the oil marketing companies had in some occasions resorted to sourcing forex from the parallel market. These operations have over the years triggered exchange rate volatility.

To stem the tide of this disruptive volatility in the exchange rate, the central bank had on several occasions intervened in the forex market by selling foreign currency to the market. Notwithstanding these interventions, the continuous oil price increase since the beginning of the post war period continues to pose a significant challenge to exchange rate management in Sierra Leone.

Based on the forgoing, the interesting question that arise from these observations in Sierra Leone are: 1) Does volatility in global oil prices lead to volatility in the Leone/US dollar? 2) If yes, what is the magnitude of the impact and is the relationship symmetric or asymmetric 3) Finally, does volatility in the Leone/US Dollar exchange rate exhibit persistence and structural breaks? Thus, understanding the relationship between oil prices and Leone/US dollar exchange rate is relevant for policy makers in the central bank, as it would assist the central bank to conduct policies that would accommodate these shocks.

In addition, it would guide them in policy design, particularly as it relates to exchange rate and its pass-through to domestic prices.

To answer the above questions, the objective of this study is to estimate the impact of fluctuations in global oil prices on the Leone/US Dollar exchange rate in Sierra Leone during the post war period, using GARCH family models with structural breaks. As far as the authors are aware, only one study has examined volatility of the Leone/US Dollar exchange rate in Sierra Leone (Milton Abdul) Thorlie et al. (2014). However, these authors did not consider the link between oil price shocks on exchange rate volatility.

Therefore, this paper contributes to the literature mainly in two ways. First, this is the first study which presents an empirical investigation of the relationship between oil price and the Leone/US Dollar exchange rate in Sierra Leone. Second, this paper employs the GARCH family models taking account of structural breaks.

The major findings of the paper is that the Leone/US dollar exchange rate is significantly influenced by global oil price shocks, as an increase in oil prices triggers a depreciation of the Leone against the US dollar. Our estimate reveals that a 10 percent increase in oil prices leads to a 0.1 percent depreciation of the Leone against the US Dollars. In addition, the result suggests that volatility in the 
Leone/US dollar exchange rate exhibits persistence, autoregressive behavior and supports asymmetric behavior. The asymmetric GARCH models indicate that positive shocks lead to a greater increase in volatility when compared to negative shocks.

The rest of the paper is organized as follows: Section 2 reviews earlier literature on the topic. Our empirical methodology and data are described in section 3. Section 4 presents the results and a number of robustness checks. This will be followed by conclusions and policy recommendations.

\section{Literature Review}

\subsection{Theoretical Review}

The theoretical literature suggests that global oil price shocks can have both supply and demand side impacts on the exchange rate (Nikbakht, 2010). The supply side impact is based on the fact that oil is a major factor-input in the production process of many non-tradable goods for oil importing counties. Therefore, any increase in oil price would affect production negatively due to increase in production costs of non-tradable goods and ultimately lead to an appreciation of the exchange rate for oil importing counties. On the demand side, oil price increase triggers excess demand for foreign currency and subsequently leads to depreciation of the domestic currency.

In the literature, three distinct channels have been identified through which oil prices and exchange rate interacts: the terms of trade channel, the wealth effect channel and the portfolio reallocation channel (Buetzer et al., 2016).

Terms of trade channel: Introduced by Amano and van Norden (1998a), the fundamental assumption of the terms of trade channel is the interaction between a tradable and non-tradable sector. In addition, in both sectors, oil is used as a major tradable input and labor as the non-tradable input in the production process and that there is perfect mobility of inputs between the two sectors with output price in the tradable sector assumed fixed.

Bénassy-Quéré et al. (2007) established a link between oil price, the price level and the real exchange rate. They assume that the impact of oil prices on the exchange rate would to a large extent depend on the energy intensity between the two sectors. If the non-tradable sector is more (less) energy intensive than the tradable one, the output price of this sector will increase (decrease) relative to the output price of tradable sector. Thus, the currency of the non-tradable sector would experience a real appreciation (depreciation) due to higher (lower) inflation

Wealth Channel: Krugman (1983) and Golub (1983) weaved a relation between oil price changes, international portfolio decision and trade balance. Fundamentally, they highlighted the distributional effect of oil price increase between oil importing and oil exporting countries. The basic idea is that oil-exporting countries experience a wealth transfer if the oil price rises. The wealth channel reflects the resulting short-run effect, while the portfolio channel assesses medium and long-run impacts. When oil prices rise, wealth is transferred to oil ex- 
porting countries (in US dollar terms) and is reflected as an improvement in exports and the current account balance in domestic currency terms. For this reason, we expect currencies of oil-exporting countries to appreciate and currencies of oil-importers to depreciate in effective terms after a rise in oil prices (Beckmann \& Czudaj, 2013). The underlying assumption is that when oil prices increase, this will require additional foreign currency i.e. increased demand for US Dollars by oil importing countries in order to finance oil importation and related petroleum products. The resulting balance of payment deficit will then translate into depreciation of the nominal exchange rate. Regards Portfolio channels there is also the possibility that the US dollar appreciates in the short-run because of the wealth effect-if oil-exporting countries reinvest their revenues in US dollar assets.

\subsection{Empirical Literature}

There is no consensus in the empirical literature concerning the relationship between oil prices and US dollar exchange rate in both oil exporting and importing economies. The literature is split between studies that suggest an appreciation of exchange rates following oil price increase (see Bénassy-Quéré et al. (2007); Narayan et al. (2008); Turhan et al. (2014)); and some studies that support the view that an increase in oil prices would result in a depreciation of the domestic currency (see Golub (1983); Krugman (1983); Bloomberg \& Harris (1995); Ghosh (2011); Aloui et al. (2013); Afees Salisu \& Mobolaji (2013); Sibanda and Mlambo (2014); Oluwatomisin et al. (2014); Jiranyakul (2015); Mishra (2016); Dauda Mohammed et al. (2019)). Meanwhile, few studies found no relationship between them (see Reboredo \& Rivera-Castro (2013); Tiwari et al. (2013); Basher, Haug, \& Sadorsky (2016)).

Among the earliest studies, Golub (1983) and Krugman (1983) concluded that for oil importing economies, an increase in oil prices would result in a depreciation of their currencies and the opposite is also true. Using the concept of the law of one price for all tradable goods, Bloomberg and Harris (1995) suggested that a depreciation of the US dollar increases the purchasing power of foreign consumers, which would trigger an increase in demand for crude oil and ultimately an increase in its price.

Ghosh (2011) using GARCH and EGARCH models on daily data for the period July 22007 to November 28, 2008, found that increase in oil price returns leads to the depreciation of the Indian currency against the US dollar. He further establishes the symmetry of the effects of positive and negative oil price shocks. Aloui et al. (2013) used the copula-GARCH approach to examine the relationship between oil prices and the U.S. dollar exchange rates of 5 foreign exchange markets-Eurozone, Canada, Britain, Switzerland, and Japan. They showed that oil price increases are associated with the depreciation of the currency. Afees Salisu and Mobolaji (2013) investigate volatility transmission between oil price and US-Nigeria exchange rate by using a VAR-GARCH model accounting for struc- 
tural breaks. Their results establish a bi-directional spillovers transmission between oil and foreign exchange markets. Sibanda and Mlambo (2014) examined the effect of global oil prices and exchange rate in South Africa using a month data spanning 1994 to 2012. Using GARCH model, the study revealed that global oil prices has a significant effect on the rand/US dollar exchange rate. Thus, an increase in global oil prices would lead to a depreciation of the South African Rand. Oluwatomisin et al. (2014) focused on the impact of oil prices and exchange rate volatility on the Nigerian economy. They observed that a proportionate change in oil price leads to a more than proportionate change in exchange rate volatility in Nigeria; which implies that the exchange rate is susceptible to changes in oil price as a global shock. Jiranyakul (2015) investigated the relationship between crude oil price and exchange rate in Thailand using cointegration and bi-variate GARCH modeling techniques for monthly data spanning 1997-2013. The result reveals no long-run relationship between crude oil price and exchange rate but that an increase volatility in crude oil prices triggers an increase in real foreign exchange volatility. Mishra (2016) employed GARCH and EGARCH models for daily data between June 2003 to March 2016 and finds that $10 \%$ oil price increase would lead to $0.15 \%$ depreciation of Indian Rupee against U.S. Dollar. Dauda Mohammed et al. (2019) applied GARCH and EGARCH models on daily data for the period July 12, 2010 to August 31, 2017 and finds that $1 \%$ oil price increases will depreciate the Nigeria Naira currency relative to the US dollar by $10 \%$.

On studies supporting an appreciation relationship between oil prices and the domestic exchange rate, Bénassy-Quéré et al. (2007) investigated the relationship between oil price and real effective exchange rate of the US dollar revealed that a 10 percent increase in oil prices resulted in about 4.3 percent appreciation of the US dollar in the long-run. Similarly, Narayan et al. (2008), variants of the Generalized Autoregressive Conditional Heteroscedasticity (GARCH) model are employed. They concluded that an increase oil prices resulted in an appreciation of the Fijian dollar. In their paper, Turhan et al. (2014) revealed that an increase in oil prices results in a significant appreciation of the domestic currency.

Finally, Reboredo and Rivera-Castro (2013) studied the relationship between oil prices and U.S. dollar using wavelet multi-resolution analysis. The results showed no evidence of a relationship prior to the global crisis, while in the post-crisis period, there was negative dependence between oil prices and exchange rates. Tiwari et al. (2013) used wavelet decomposition to test linear and nonlinear causality within different frequency bands. The results showed no relationship at lower time scales. Basher, Haug and Sadorsky (2016) examined the relationship between oil prices and exchange rate and concluded that the result offers limited support for the relationship between these variables.

Specific to the Sierra Leone economy, Milton Abdul Thorlie et al. (2014) investigated the accuracy and forecasting performance of the Leone/US dollar exchange rate return using GARCH family models without an exogenous variable. 
The study found that the Asymmetric (GARCH) and GARCH models better fit under the non-normal distribution than the normal distribution and improve the overall estimation for measuring conditional variance while the GJR-GARCH model using the skewed Student $\mathrm{t}$-distribution is most successful and better forecast the Sierra Leone exchange rate volatility.

From the empirical review it is difficult to draw a single conclusion about the impact of global oil price shocks on the exchange rate across countries. Results from the review suggest that global oil price shocks affect oil exporting and importing economies differently.

In most of the studies, volatility in global oil prices leads to a depreciation of the exchange rate of oil importing economies and the inverse is true for oil exporting economies. There are few studies in which an increase in crude oil prices was associated with an appreciation of the exchange rate in an oil importing economy. The conflicting conclusions could be due to differences in the models adopted, choice of variables and the estimation techniques used.

\section{Data and Methodology}

\subsection{Definition of Research Variables, Data Transformation and Sources of Data}

The study employs time series data of monthly average Leones/US Dollar exchange rate and crude oil. Data on global oil price was sourced from the World Bank Commodity Price Data (The Pink Sheet) while the monthly data on exchange rate was sourced from the IMF international financial statistics database. The crude oil price represents the average spot price of Brent, Dubai and West Texas. The sample covers post war reform period from $2002 \mathrm{~m} 01$ to $2020 \mathrm{~m} 05$. The bilateral exchange rate is define as the unit of domestic currency (i.e. Leones) per unit of US dollars, implying that an increase represents a nominal depreciation of the Leones against the US dollars and vice versa.

The original series were seasonal adjustment using Census $\mathrm{X}-13$ and $\mathrm{X}-11$ ARIMA method. The seasonally adjusted series was then used to construct the returns series for both oil price and exchange rate as follows:

$$
\begin{gathered}
r_{\text {ert }}=\log \left(\frac{E R_{t}-E R_{t-1}}{E R_{t-1}}\right) \\
r_{\text {oilt }}=\log \left(\frac{O I L \_P_{t}-O I L \_P_{t-1}}{O I L \_P_{t-1}}\right)
\end{gathered}
$$

where $r_{e r t}$ is the returns on exchange rate series at period $t . E R_{t}$ is the exchange rates of the Leones against the US Dollars at period $t . E R_{t-1}$ is one period lag of the exchange rate. $r_{\text {oilt }}$ is the returns on global oil price. $O I L_{-} P_{t}$ is global oil price at period $t$. OIL_P $P_{t-1}$ is one period lag of global oil price.

\section{Descriptive Statistics}

Table 1 presents the descriptive statistics of the original series and their respective returns for both exchange rate and global oil price. 
Table 1. Summary statistics of exchange rate and oil price returns.

\begin{tabular}{ccccc}
\hline Statistic & $\boldsymbol{E} \boldsymbol{R}_{\boldsymbol{t}}$ & $\boldsymbol{r}_{\text {ert }}$ & OIL_P & $\boldsymbol{r}_{\boldsymbol{t}}$ \\
\hline Mean & 4597.66 & 0.007371 & 67.25892 & 0.000721 \\
Median & 4321.825 & 0.005815 & 62.00589 & 0.013721 \\
Maximum & 9771.956 & 0.049874 & 132.8252 & 0.347848 \\
Minimum & 2018.14 & -0.007019 & 21.04333 & -0.486293 \\
Range & $\mathbf{7 7 5 3 . 8 1 6}$ & $\mathbf{0 . 0 5 6 8 9 3}$ & $\mathbf{1 1 1 . 7 8 1 8 7}$ & $\mathbf{0 . 8 3 4 1 4 1}$ \\
Sted Dev & 2092.662 & 0.00946 & 26.62757 & 0.094902 \\
Skewness & 1.000376 & 1.639284 & 0.325026 & -1.520771 \\
Kurtosis & 2.90501 & 7.345854 & 2.120268 & 9.687819 \\
Jargue -Bera Stat & 36.10828 & 265.4843 & 10.76846 & 483.5521 \\
Probability of Jargue-Bera Stat & 0.00000 & 0.00000 & 0.004588 & 0.000000 \\
\hline
\end{tabular}

Source: Authors' computation with EViews version 10.

From Table 1, one would conclude that the original series of the exchange rate is more volatile than the global price of oil as the former has higher standard deviation (i.e. 2092.662) than the later (i.e. 26.62757). With regards the returns series, oil price is more volatile than exchange rate with the former having a higher standard deviation (i.e. 0.094902) than the later (i.e. 0.00946). In terms of the statistical distribution of the series, both the original series for the exchange rate and oil price exhibit positive skewness suggesting that their right tails are particularly extreme. The exchange rate returns also show positive skewness while oil price returns is negatively skewed. In terms of Kurtosis, the original series for both the exchange rate and oil price show platykurtic distribution indicating less peak in the mean with thinner tails, and more of the distribution in the shoulders than a normal distribution. On the other hand both the exchange rate and oil price returns are leptokurtic distributions indicating fatter tails with more peaked at the mean than a normally distributed random variable. Finally, the Jacques-Bera statistic shows that both the original and returns series departed from normality.

Figure 1 illustrates the evolution of oil prices and exchange rates during the period from January 2002 until May 2020. From the left panel of Figure 1, trend in oil price and oil price returns exhibit unsteady patterns. Secondly, the trends in oil price returns suggest evidence of volatility clustering as periods of high volatility are followed by periods of relatively low volatility. Thirdly, oil price spikes were observed during 2007 to 2009 which coincided with the global financial crisis. It was also observed that oil price slump occurred in March 2020, a period that coincides with the global recession caused by COVID-19. These observations of volatility and structural shocks partly explain why oil price returns are more volatile than the exchange rate returns as evidenced in Table 1.

From the right panel of Figure 1, trends in the original exchange series exhibited an upward trend whiles exchange returns displayed unsteady pattern. As 

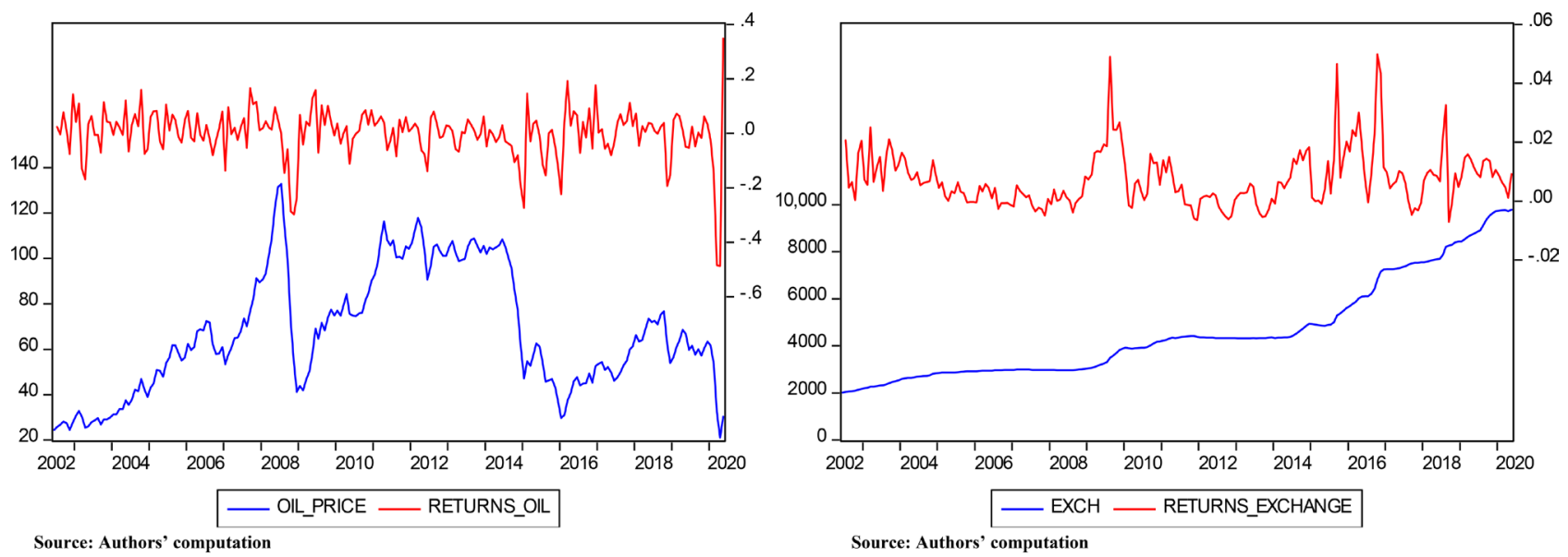

Figure 1. Combined graph of oil price, oil price returns, exchange rate and exchange rate returns.

with oil price returns, the exchange rate returns shows sign of volatility clustering. Furthermore, exchange spikes were observed in August 2009 (i.e. era of the world financial crisis period), September 2015 and October 2018. Notable decline in exchange rate returns occurred in April 2020; again a period that coincided with oil price slumps arising from the impact of the COVID-19.

To conclude, the fact that both the exchange rate and oil price returns exhibit features of volatility clustering, Leptokurtosis and non-normality, suggest that, the use of non-liner models are appropriate in modeling such series (See for example Wilhelmsson, 2006). Examples of such non-linear models are Autoregressive conditionally heteroscedastic (ARCH) models and Generalized Autoregressive Conditional (GARCH) models.

\section{Testing for Unit Root}

One of the pre-condition for estimating GARCH family models is the assumption that all the variables must be stationary, as most time series variable exhibit non stationary properties which could lead to spurious results. Drawing from the literature, there is strong evidence to suggest that oil price and exchange rate dynamics are subject to structural breaks. Thus, in modeling oil price-exchange rate nexus it is important to take account of structural break in the data (see Reboredo (2012); Zhang (2013); Turhan (2014); Beckmann \& Schüssler (2016)). Furthermore, Perron (1989) suggest that the conventional unit root tests are biased toward a false unit root null when the data are trend stationary with a structural break.

Against this background, we draw from Perron (1989), Perron and Vogelsang (1992), and Vogelsang and Perron (1998) to confirm the stationary properties of the two series by conducting unit root tests with a breakpoint. (For detail on the variants of these tests, see EViews manual, version 9, pages 557 to 572). Table 2 report the results on units root with break tests.

Based on the test statistic reported in the third column of Table 2, we reject the unit root null hypotheses for both series. Thus, we conclude that both exchange rate returns and oil price returns are stationary in levels when we accounted for 
structural breaks.

The fourth column indicates that the break date for the exchange returns occurred in September 2015. This date coincided with the period of the Ebola outbreak in Sierra Leone resulting in slowdown in the economy that triggered volatility in the exchange. The fourth column further shows that the break date for oil price returns occurred in November 2008. This period coincided with the global financial crisis which stimulated speculation in the crude oil futures markets, resulting in upward swings in oil prices.

The fifth column in Table 2 indicate that the coefficients of the break dummies are statistically significant, thus reinforcing evidence of structural breaks in both series at the selected break dates.

\section{Testing for ARCH effects in Exchange Rate and Oil Returns}

To test whether ARCH-effects are present in the two series, we follow the three steps approach of ARCH-LM test proposed by Engle (1982). The first step is to specify and estimate an appropriate model by OLS and obtain the fitted residuals. To achieve this, we regress each of the returns series on a constant and 169 alternative order of ARMA terms. We then employed the Schwarz information criterion within the Box-Jenkins framework to identify and select an appropriate ARMA model that adequately capture the dynamic features of the return series.

As reflected in Figure 2, the ARMA criteria graph suggests ARMA $(1,0)$ for

Table 2. Perron unit root with break test on oil price returns and exchange rate returns.

\begin{tabular}{cccccc}
\hline Variable & $\begin{array}{c}\text { Trend } \\
\text { Specification }\end{array}$ & $\begin{array}{c}\text { ADF Test } \\
\text { Statistic }\end{array}$ & Break Date & $\begin{array}{c}\text { Coefficient of Break } \\
\text { Dummy (P Values) }\end{array}$ & Conclusion \\
\hline$r_{\text {ert }}$ & Intercept & $7.698989(0.0000)^{* * *}$ & $2015 \mathrm{M} 09$ & $0.034223(0.0000)^{* * *}$ & $\mathrm{I}(0)$ \\
$r_{\text {oilt }}$ & Intercept & $11.16924(0.000)^{* * *}$ & $2008 \mathrm{M} 11$ & $0.232518(0.0135)^{* *}$ & $\mathrm{I}(0)$ \\
\hline
\end{tabular}

Source: Author's computation using Eviews10. Note: The probability values are indicated in parentheses. Critical values from the Test Statistic with intercept at $10 \%, 5 \%$ and $1 \%$ are $-4.193649,-4.443649$ and -4.949133 respectively.
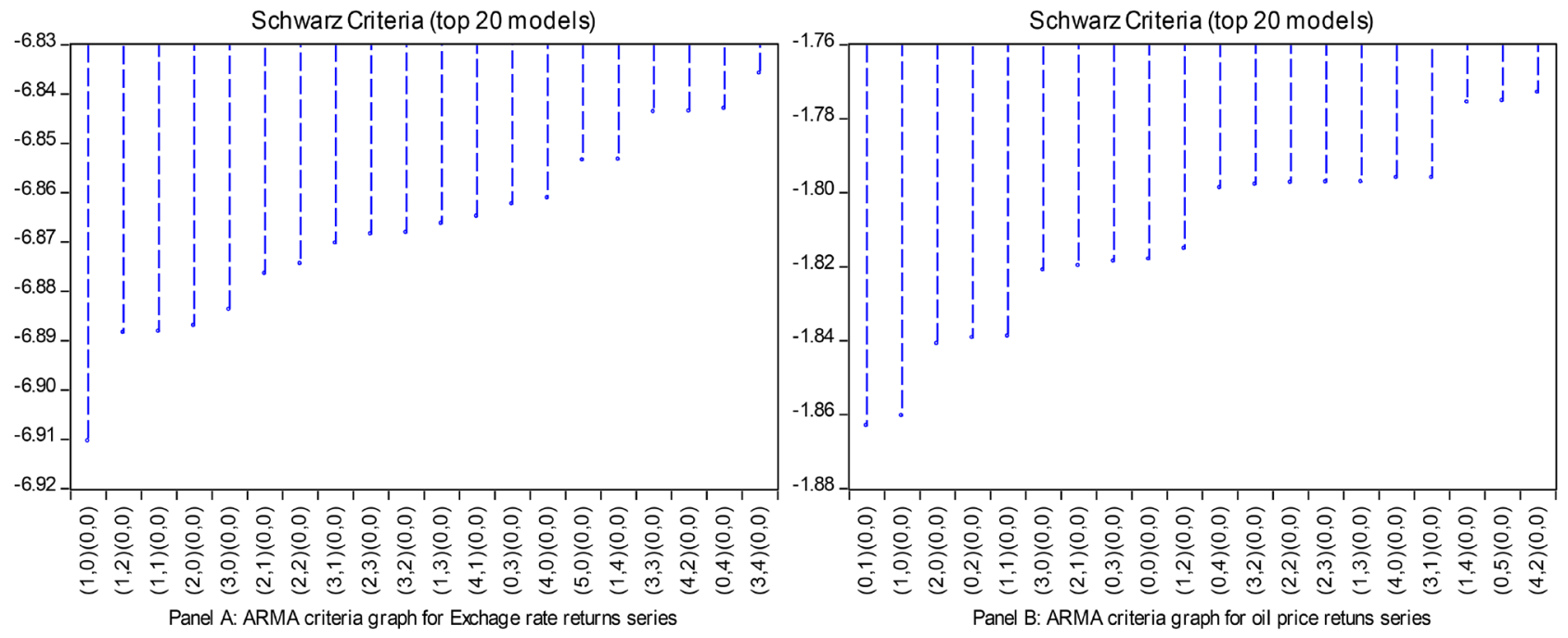

Figure 2. Combine ARMA criteria graph for exchange rate and oil price returns. 
the exchange rate returns and ARMA $(0,1)$ for oil price returns as the most appropriate model among the top 20 models selected from the 169 models estimated.

Based on the ARMA criteria graphs, we therefore specify the following univariate models for the two series:

$$
\begin{aligned}
& r_{\text {ert }}=\lambda+\delta r_{e t-1}+\varepsilon_{t} \\
& r_{\text {oilt }}=\omega+\zeta \varepsilon_{t-1}+\varepsilon_{t}
\end{aligned}
$$

where $r_{\text {ert }}$ and $r_{\text {oilt }}$ denote exchange rate returns and oil price returns respectively and are measured as indicated by Equations (1) and (2) $\varepsilon_{t} \sim \operatorname{IDD}\left(0, \sigma^{2}\right)$

As proposed by Engle (1982), the second step in ARCH-LM test is to Square the fitted residuals and regress them on a constant and $k$ lags of the squared fitted residuals as specified in the following equation:

$$
\varepsilon_{t}^{2}=\lambda_{0}+\lambda_{1} \varepsilon_{t-1}^{2}+\lambda_{2} \varepsilon_{t-2}^{2}+\cdots+\lambda_{k} \varepsilon_{t-k}^{2}+u_{t}
$$

The third step involves the LM tests for the joint null hypothesis that there is no ARCH effect in the model: i.e. $\lambda_{1}=\lambda_{2}=\lambda_{3}=\lambda_{k}=0$. In empirical application, the F-statistics can be use or one can use the test statistic defined as $\mathrm{TR}^{2}$ (i.e. the number of observations multiplied by the coefficient of multiple correlation obtained from Equation (5)). The test statistics is a chi-square distribution; $\chi^{2}(k)$-with $k$ degrees of freedom which represent the number of autoregressive terms in Equation (9). Table 3 presents the results for the residual ARCH effects.

From Table 3, it can be concluded that there is evidence of ARCH effects in both series at all chosen lags as judged by the results of both the $\mathrm{F}$ and $\mathrm{TR}^{2}$ tests statistics. For the exchange rate returns (See Panel A), both the F and $\mathrm{TR}^{2}$ test statistics are statistically significant at $5 \%$ level for lags 1 and 15 . Also they are statistically significant at $10 \%$ for lag 25 .

For the oil price returns (See Panel B), the tests statistics at all three chosen lags are statistically significant at $1 \%$. Thus, the test statistics resoundingly reject

Table 3. Test for the residual ARCH effects in exchange rate and oil price returns.

\begin{tabular}{ccc}
\hline & \multicolumn{2}{c}{ PANEL A: ARCH-LM Test for rert } \\
\hline K Lag Length & F-statistic (p-Value) & Obs $^{*}$ R-squared (p-value) \\
\hline 1 & $11.48538(0.0008)^{* *}$ & $10.9979(0.0009)^{* *}$ \\
15 & $1.736397(0.0473)^{* *}$ & $24.80025(0.0527)^{*}$ \\
25 & $1.52444(0.0630)^{*}$ & $35.82729(0.0743)^{*}$ \\
\hline K Lag Length & PANEL B: ARCH-LM TEST for roil \\
\hline 1 & F-statistic(p-Value) & Obs ${ }^{*}$ R-squared $(\mathrm{p}-\mathrm{value})$ \\
\hline 15 & $152.3279(0.0000)^{* * *}$ & $89.4748(0.0000)^{* * *}$ \\
25 & $12.16134(0.0000)^{* * *}$ & $99.56883(0.0000)^{* * *}$ \\
\hline $\begin{array}{l}\text { Source: Author's computation using Eviews } 10 ; \text { Note: Probability values are in parenthesis. }{ }^{*},{ }^{* *} \text { and } \\
\text { plies significant at } 10 \%, 5 \% \text { and } 1 \% \text { level of significant respectively. }\end{array}$
\end{tabular}


the null hypothesis of no-ARCH effect in both series. This is consistent with the results derived in Table 1 which illustrates the existence of large swings in the series with non-normality features. These findings further justify the use of volatility models in this study.

\subsection{Specification of the GARCH and EGARCH Models}

Since there is evidence of structural breaks and ARCH effects in our model, we modified the work of Narayan et al. (2008), Ghosh (2011), Mishra (2016) and Dauda Mohammed et al. (2019) to specify the following mean equation for the ARMA $(1,0)-G A R C H(1,1)$ model:

$$
r_{t}=\lambda+\delta r_{t-1}+\gamma r_{o i l}+\eta_{1} D_{t}\left(T_{b}\right)+\eta_{2} D U_{i}\left(T_{b}\right)+\varepsilon_{t}
$$

We use the nominal price of oil as a proxy for exogenous changes in the terms of trade consistent with the terms of trade channel. $\lambda>0$ or $\lambda<0, \delta>0$ or $\delta<0, \gamma>0, \eta_{1}>0, \eta_{2}>0$ and $\varepsilon_{t}=$ is error term with ARCH effects defined as $\varepsilon_{t}=\sigma_{t} e_{t}$. Where $e_{t} \sim\left(\operatorname{IDD}\left(0, \sigma^{2}\right), r_{o i l t}\right.$ is oil price returns, $\lambda$ is a constant, $r_{t-1}$ is one period lag of exchange rate returns as suggested by ARMA graph criteria in Figure 2, $r_{\text {oilt }}$ is oil price returns. The first dummy variable: $D_{t}\left(T_{b}\right)=1\left(t=T_{b}\right)$ is a one-time break dummyvariable which takes the value of 1 only on the break date and 0 otherwise. The second dummy: $D U_{t}\left(T_{b}\right)=1\left(t \geq T_{b}\right)$ is an intercept break variable that takes the value 0 for all dates prior to the break, and 1 thereafter. The variance equation for the $\operatorname{ARMA}(1,0)$ - GARCH $(1,1)$ model can be specify as:

$$
\sigma_{t}^{2}=\partial+\theta \varepsilon_{t-1}^{2}+\rho \sigma_{t-1}^{2}
$$

where: $\partial$ is a constants term $\varepsilon_{t-1}^{2}$ is the ARCH term: i.e. news about volatility from the previous period, measured as the lag of the squared residual from the mean equation. $\sigma_{t-1}^{2}$ is the GARCH term: i.e. last period's forecast variance. Furthermore, we modified the GARCH $(1,1)$ model to specify the GARCH in Mean model as follow:

$$
r_{t}=\lambda+\delta r_{t-1}+\gamma r_{\text {oil }}+\phi \log \sigma_{t}^{2}+\eta_{1} D_{t}\left(T_{b}\right)+\eta_{2} D U_{i}\left(T_{b}\right)+\varepsilon_{t}
$$

The symbol $\phi$ can be viewed as a risk premium. If $\phi$ is positive and statistically significant it will reflect increase risk, reflected in an increase in the conditional variance and leading to a rise in the mean return. Equations (6) to (8) represent symmetric volatility models.

These models assume that a symmetric response of volatility to positive and negative shocks. However, it has been argued in finance literature that a negative shock to financial time series is likely to cause volatility to rise by more than a positive shock of the same magnitude. To test whether this hypotheses hold in the Sierra Leone contest, we therefore adopted the following exponential GARCH model proposed by Nelson (1991):

$$
\log \left(\sigma_{t}^{2}\right)=\partial+\beta \log \left(\sigma_{t-i}^{2}\right)+\alpha\left|\frac{\varepsilon_{t-1}}{\sigma_{t-1}}\right|+\tau \frac{\varepsilon_{t-1}}{\sigma_{t-1}}
$$


If $\tau$ is statistically significant and negative then asymmetric and leverage effects are present. This means that negative shocks increases volatility more than positive shocks of the same magnitude. On the other hand, if $\tau$ is statistically significant and positive then asymmetric effects is present and positive shocks increases volatility more than negative shocks of the same (for details See Eviews 9 User's Guide 2 page 345). Also see Chris Brooks (2008); page 406. The estimate of $\beta$ allows for an evaluation of the persistence of shocks. Nelson (1991) shows that an absolute of $\beta$ less than one (1) ensures stationarity and ergodicity of the $\operatorname{EGARCH}(p, q)$.

The model has several advantages over the pure GARCH specification. First, asymmetries are allowed for under the EGARCH formulation, second, since the $\log \left(\sigma^{2}\right)$ is modelled, then even if the parameters are negative, $\sigma^{2}$ will be positive. Thus no need to artificially impose non-negativity constraints on the model parameters as it is the case for symmetric models.

\section{Evaluation of Models and Model Selection Criteria}

To complete the basic GARCH specification, assumptions must be made about the conditional distribution of the error term. In empirical application, there are five assumptions commonly employed when working with GARCH models: normal (Gaussian) distribution, Student's $t$-distribution, Student's $t$-distribution with fixed degrees of freedom, the Generalized Error Distribution (GED) and the Generalized Error Distribution (GED) with fixed parameter.

All of these alternative distributional assumptions are considered in the estimation of each volatility model specified above and we employed three information criteria to determine the model that best fit the data. The three information criteria considered for model diagnosis include Schwartz, Akaike and Hannan-Quinn information criteria. Table 4 present our findings on this issue.

From Panel A and B in Table 4, the three information criteria suggest that models with student's t-distribution error assumption performed better than the other error distribution assumption models. According to panel C, two of the information criteria namely AIC and HQ suggest that models with student's $\mathrm{t}$-distribution error assumptions performed better than models with other error distribution assumptions. Since majority of the information criteria support models with student's t-distribution errors, we therefore estimated the GARCH models using the student distributing error assumptions.

\section{Results and Discussion}

Table 5 presents the results of the estimated GARCH $(1,1)$, GARCH-M $(1,1)$ and EGARCH $(1,1)$ models for Sierra Leone. The second column in Table 5 shows that the estimated parameters in the GARCH $(1,1)$ model have the expected signs and all of them are statistically significant at most at $5 \%$. This clearly shows that oil price, ARCH and GARCH terms accounts for exchange rate variations in Sierra Leone. It can also be concluded that past variations in exchange rate significantly affect current variations in exchange rate. 
Table 4. Model diagnosis for selection of error distribution assumptions.

\begin{tabular}{|c|c|c|c|c|c|}
\hline \multicolumn{6}{|c|}{ PANEL A. ARMA $(1,0)$-GARCH $(1,1)$ MODELS } \\
\hline Selection Criteria & Normal & Student- $t$ & Student Fixed & GED & GED_Fixed \\
\hline SIC & -7.326 & -7.477 & -7.451 & -7.466 & -7.433 \\
\hline AIC & -7.452 & -7.619 & -7.577 & -7.607 & -7.558 \\
\hline HQI & -7.326 & -7.561 & -7.526 & -7.550 & -7.508 \\
\hline \multicolumn{6}{|c|}{ PANEL B. ARMA $(1,0)$-GARCH $(1,1)$ IN MEAN MODELS } \\
\hline Selection Criteria & Normal & Student-t & Student Fixed & GED & GED_Fixed \\
\hline SIC & -7.303 & -7.454 & -7.427 & -7.432 & -7.408 \\
\hline AIC & -7.444 & -7.612 & -7.568 & -7.589 & -7.549 \\
\hline HQI & -7.387 & -7.548 & -7.511 & -7.526 & -7.492 \\
\hline \multicolumn{6}{|c|}{ PANEL C. ARMA $(1,0)$ - E-GARCH $(1,1)$ MODELS } \\
\hline Selection Criteria & Normal & Student- $t$ & Student Fixed & GED & GED_Fixed \\
\hline SIC & -7.426 & -7.491 & -7.495 & -7.487 & -7.491 \\
\hline AIC & -7.567 & -7.648 & -7.636 & -7.645 & -7.632 \\
\hline HQI & -7.510 & -7.585 & -7.579 & -7.581 & -7.575 \\
\hline
\end{tabular}

Source: Author's computation using Eviews10.

These findings are consistent with the outcome of previous studies such as Milton Abdul Thorlie et al. (2014), Narayan et al. (2008), Ghosh (2011), Shekhar Mishra (2016) etc. The sum of the coefficients of the ARCH and GARCH term in the variance equation of 0.95 is large, indicating that the changes in the conditional variance are persistent (large positive or negative return will lead to future forecasts of the variance to be high for a long period). Likewise, the GARCH $(1,1)$ coefficients are positive confirming the non-negativity condition of the model.

Column three in Table 5 shows that the estimated parameters in the GARCH$\mathrm{M}$ model also have the expected signs and all of them are statistically significant with the exception of the risk premium parameter. The estimated risk premium parameter on the mean equation has a positive sign (i.e. $\varnothing=0.000687$ ) but is not statistically significant. This means that there is no feedback from the conditional variance to the conditional mean. The model also satisfies the stationarity conditions as the sum of their ARCH and GARCH terms in the variance equations is less than one (i.e. the sum of $\mathrm{ARCH}$ and GARCH terms (i.e. $\theta+\rho$ ) is 0.96 ). Given that the sum is close to one indicate a slow mean reverting variance process for the estimated GARCH-M model. Furthermore, the model satisfy the non-negativity conditions as their estimated parameters in the variance equations are greater than zero.

With regards the asymmetric model, the fourth column indicate that the estimated parameter in the EGARCH $(1,1)$ model also have the expected signs and are all statistically significant. Furthermore, the model satisfies the stationary condition as the GARCH term in the variance equation is less than one (i.e. $ß=0.888288<1$ ). 
Table 5. Results of the GARCH $(1,1)$, GARCH-MEAN $(1,1)$ and EGARCH $(1,1)$ Models

\begin{tabular}{|c|c|c|c|}
\hline Variable & $\operatorname{GARCH}(1,1)$ & GARCH-MEAN $(1,1)$ & EGARCH $(1,1)$ \\
\hline \multicolumn{4}{|l|}{ Mean Equation } \\
\hline$\Lambda$ & $0.002688(0.0238)^{\star \star}$ & $0.011773(0.0888)^{*}$ & $0.003084(0.0184)^{* *}$ \\
\hline$\delta$ & $0.74664(0.0000)^{\star * *}$ & $0.715574(0.0000)^{* * *}$ & $0.757919(0.0000)^{* * *}$ \\
\hline$\Gamma$ & $0.005732(0.0267)^{\star *}$ & $0.005499(0.0295)^{\star *}$ & $0.005949(0.0202)^{* *}$ \\
\hline$\eta_{1}$ & $0.033167(0.0000)^{* * *}$ & $0.032872(0.0000)^{\star \star \star}$ & $0.033322(0.0000)^{* * *}$ \\
\hline$\eta_{2}$ & $0.00528(0.0415)^{\star *}$ & $0.00497(0.0404)^{* *}$ & $0.005612(0.0436)^{* *}$ \\
\hline$\varnothing$ & & $0.000687(0.1841)$ & \\
\hline \multicolumn{4}{|l|}{ Variance Equation } \\
\hline$\partial$ & $0.00000484(0.0774)^{*}$ & $0.00000461(0.0782)^{*}$ & $1.363097(0.0073)^{* *}$ \\
\hline$\Theta$ & $0.356428(0.0289)^{\star \star}$ & $0.339999(0.0257)^{\star \star}$ & \\
\hline $\mathrm{P}$ & $0.597764(0.0000)^{* * *}$ & $0.619591(0.0000)^{\star * *}$ & \\
\hline$\alpha$ & & & $0.223355(0.0911)^{*}$ \\
\hline$ß$ & & & $0.888288(0.0000)^{* * *}$ \\
\hline$\tau$ & & & $0.230081(0.0137)^{* *}$ \\
\hline \multicolumn{4}{|l|}{ Diagnostics } \\
\hline \multicolumn{4}{|l|}{ Information Criteria } \\
\hline SIC & -7.477011 & -7.454373 & -7.490884 \\
\hline AIC & -7.618571 & -7.611662 & -7.648173 \\
\hline HQ & -7.561368 & -7.548103 & -7.584614 \\
\hline Adjusted R-squared & 0.495111 & 0.50106 & 0.495087 \\
\hline \multicolumn{4}{|l|}{ Correlogram Q statistics } \\
\hline Q-Statistics (Lag 1) & $0.0711(0.790)$ & $0.4776(0.490)$ & $0.0552(0.814)$ \\
\hline Q-Statistics (Lag 15) & $11.956(0.682)$ & $17.589(0.285)$ & $9.6633(0.840)$ \\
\hline Q-Statistics (Lag 36) & $36.905(0.427)$ & $38.006(0.378)$ & $35.038(0.514)$ \\
\hline \multicolumn{4}{|c|}{ Correlogram Squared Residuals } \\
\hline Q-Statistics (Lag 1) & $0.0416(0.838)$ & $0.6248(0.429)$ & $0.0015(0.969)$ \\
\hline Q-Statistics (Lag 15) & $7.7519(0.933)$ & $10.049(0.817)$ & $9.5627(0.846)$ \\
\hline Q-Statistics (Lag 36) & $13.883(1.000)$ & $19.935(0.986)$ & $23.972(0.938)$ \\
\hline \multicolumn{4}{|l|}{ Heteroskedasticity } \\
\hline \multicolumn{4}{|l|}{ ARCH-LM (Lag 1) } \\
\hline F-Stat & $0.040434(0.8408)$ & $0.610184(0.4356)$ & $0.001466(0.9695)$ \\
\hline $\mathrm{NR}^{2}$ & $0.04081(0.8399)$ & $0.614191(0.4332)$ & $0.001479(0.9693)$ \\
\hline \multicolumn{4}{|l|}{ ARCH-LM (Lag 15) } \\
\hline F-Stat & $0.463764(0.9558)$ & $0.727575(0.7545)$ & $0.7664(0.7134)$ \\
\hline $\mathrm{NR}^{2}$ & $7.287646(0.9492)$ & $11.19988(0.7383)$ & $11.76222(0.6969)$ \\
\hline \multicolumn{4}{|l|}{ ARCH-LM (Lag 36) } \\
\hline F-Stat & $0.306398(1.0000)$ & $0.606868(0.9589)$ & $0.688864(0.9035)$ \\
\hline $\mathrm{NR}^{2}$ & $12.9145(0.9999)$ & $23.88011(0.9393)$ & $26.62403(0.8725)$ \\
\hline
\end{tabular}

Source: Author's computation using Eviews10. 
In terms of the comparative performance of the volatility models, the GARCH $(1,1)$ appears to perform better than the GARCH $(1,1)-\mathrm{M}$ mean as the values of its information criteria are lower compared with those of GARCH $(1,1)-\mathrm{M}$ model.

This is expected as the inclusion of the risk premium variable in the conditional mean equation is statistically insignificant and hence does not add any useful information to the volatility of exchange rate returns.

However, the EGARCH $(1,1)$ appears to have a better fit over the GARCH $(1$, 1) model as the values of its information criteria are lower than those of GARCH $(1,1)$ model. Overall, we therefore conclude that the asymmetric model EGARCH $(1,1)$ appears superior to the symmetric models. Hence the analyses of our empirical results will focus on the EGARCH $(1,1)$ model.

The Mean equation of the EGARCH $(1,1)$ model (see column four) shows that there is an autoregressive process in the exchange rate, indicated by the significance of the lagged exchange rate term at $1 \%$ level (i.e. $B=0.757919$ ). This means that exchange rate variations in the previous period significantly affect exchange rate variations in the current period. Also column four shows that an increase in oil price (i.e. $\uparrow$ in $\Gamma$ ) has a positive impact on the nominal exchange rate (i.e. $r_{\text {ert }}$ will $\uparrow$ ). This implies that an increase in oil price returns leads to depreciation of the Leones against the US Dollars. In particular, a 10\% increase in oil price leads to about $0.1 \%$ depreciation of the Leones against the US Dollars. Hence our empirical findings lend credence to the terms of trade channels/wealth effect and balance of payment channel. This result is consistent with the findings of previous studies on oil price exchange rate nexus. For example, Amano \& Van Norden (1998b) found that a 10 percent rise in oil prices led to a depreciation of the mark and the yen by roughly 0.9 percent and 1.7 percent respectively. Fratzscher et al. (2014) revealed that a $10 \%$ increase in the price of oil led to a depreciation of the US nominal effective exchange rate by $0.28 \%$. Shear Mishra (2016), finds that $10 \%$ oil price increase would lead to $0.15 \%$ depreciation of Indian Rupee against U.S dollars.

Both the break dummy and the intercept break dummy are positive and statistically significant indicating evidence of structural breaks. In particular, the estimated coefficient of the break dummy indicate that on September, 2015, there was a $0.033 \%$ one-off increase in the returns for exchange rate. This coefficient is statically significant at $1 \%$. The estimated coefficient of the intercept dummy indicates that the mean of the exchange rate returns shitted upwards by $0.005 \%$ since September 2015 onwards. This coefficient is statistically significant at 5\%. These findings are consistent with the Perron (1989) unit root with break test results reported in Table 2 and thus further reinforces the evidences of structural break in exchange rate returns.

Additionally, our empirical results lend support to previous studies such as Reboredo (2012), Zhang (2013), Turhan et al. (2014) and Beckmann \& Schüssler (2016) also found that structural breaks are statistically significant in models of 
oil price and exchange rate nexus.

It should be noted that the selected structural break date reflects domestic macroeconomic shocks in 2015 that was occasioned by the outbreak of Ebola epidemic. In particular, the break date coincided with almost the end of the Ebola outbreak in Sierra Leone. Consequently, foreign donor inflows for Ebola containment measures had decline significantly while the economy was recovering slowly and imports were picking up. Also, the key mining companies which are the major source of exports to the country were yet to resume operations. The combination of these factors culminated into external sector challenges which had implications for exchange rate volatility and regime shifts in exchange dynamics.

From the variance equation, the estimated volatility persistent coefficient (i.e. $\beta=0.8882888$ ) is high and statistically significant at $1 \%$. This is an indication that there is high level of persistence in the volatility of exchange rate returns in Sierra Leone. In other words, when there is a shock to exchange rate volatility, it will take a long time for the impact of such a shock to die out. However the degree of persistence is relatively lower compared with those in the symmetric model. The coefficient of the ARCH term (i.e. $\alpha$ ) is roughly 0.223355 and is statistically significant at $10 \%$. This mean that a $10 \%$ increase in previous periods' volatility will leads to an increase of $2 \%$ in current volatility of the exchange rate returns. The coefficient on the variable measuring the asymmetric effect (i.e. $\tau=$ 0.230081 ) is positive and statistically significant at $5 \%$. This means that positive shocks has the potential to increase volatility of exchange rate returns more than negatives shocks of the same magnitude. In other worlds, depreciation of the Leone against the US dollars will lead to higher next period volatility than when the Leone appreciate against the US dollars. This finding is consistent with the work of Chris Brooks (2009)

\section{Post estimation diagnostic tests}

As indicated in the lower panel of Table 5, the Correlogram-Q statistics at all chosen lags are not statically significant at the conventional levels. This means that there is no evidence of serial correlation in the mean equation. These results suggest that the mean equation is correctly specified. The Correlogram Squared Q-statistics at all chosen lags are not statically significant at the conventional levels indicating that there is no evidence of $\mathrm{ARCH}$ in the variance equation and therefore it is correctly specified.

The ARCH LM Test reveals that both the F and $\mathrm{TR}^{2}$ statistics are not statistically significant at the conventional levels implying that there is no evidence of $\mathrm{ARCH}$ in the variance equation. Finally, the adjusted R squared is 50 percent. This means that the model account for about 50 percent of the variation in exchange rate. This implies that the model reasonably fit the data well.

Figure 3 depict the conditional variance of exchange rate returns. A close look at the graph reveals evidence of notable spikes. However there is no spike on the break date indicating that the estimated model has adequately controlled for structural breaks. This observation further supports the significance of accounting 


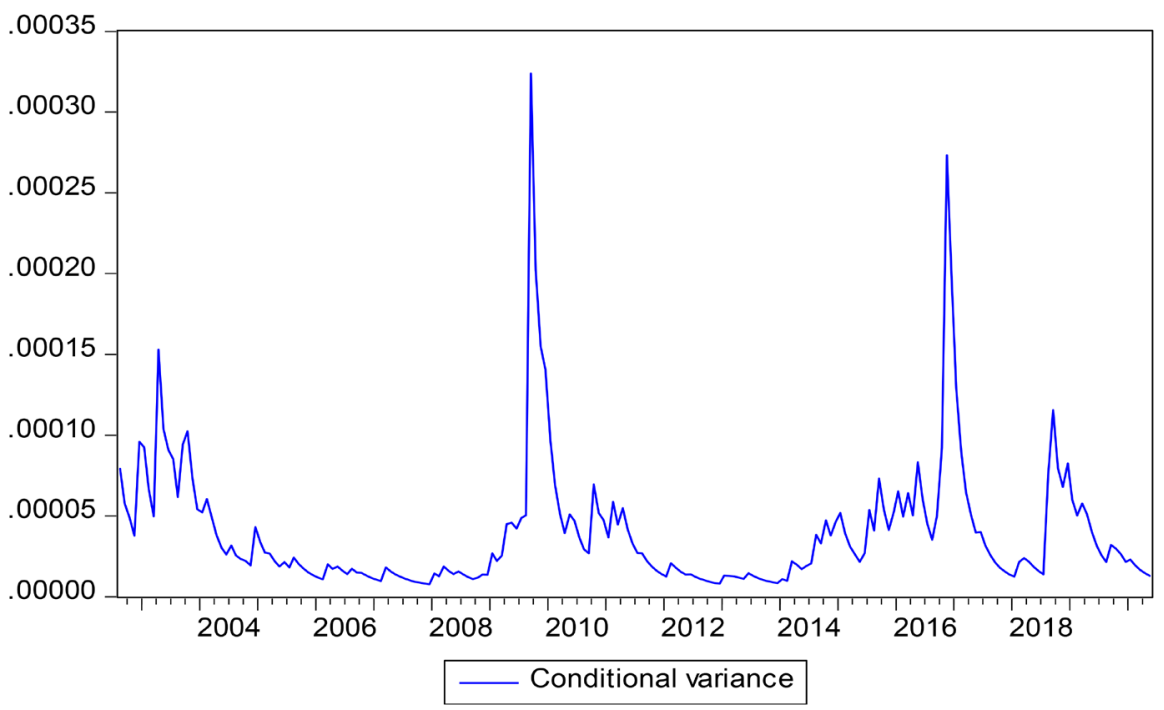

Figure 3. Conditional Variance for exchange rate returns from ARMA $(1,0)$ and EGARCH $(1,1)$ Model.

for structural break in modeling the impact of oil price on exchange rate.

\section{Conclusion}

Establishing a relation between global oil price and the Leone/US Dollar exchange rate in Sierra Leone is crucial based on the fact that Sierra Leone is an oil importing country with petroleum products on average accounting for about 20 percent of total imports. In addition, petroleum products are a major input in most economic activities especially in transport, manufacturing and mining sectors. This paper aims at examining the nexus between global oil prices and the Leone/US Dollar exchange rate in Sierra Leone. To achieve the objective of the paper, ARCH/GARCH models were utilized with structural break for the post war period spanning 2002M6 to 2020M5.

After establishing the existence of $\mathrm{ARCH}$ effects and ensuring the stationarity of the data set, the paper applied both GARCH $(1,1)$ and $\operatorname{GARCH}(1,1)$ in Mean models to capture the symmetry effect between global oil prices and exchange rate. Also, the paper employs exponential GARCH (EGARCH $(1,1))$ model to capture the asymmetry in the relationship between global oil prices and Leone/US Dollar exchange rate. The model selection reveals that the student's distribution provides better fit compared to the alternatives. Of the three models estimated, the EGARCH $(1,1)$ model was found to have the best fit for modelling exchange rates and global oil price shocks in Sierra Leone since all the coefficients of the mean and variance equation are found to be statistically significant and have the least values based on the information criteria.

The results show that the oil price-exchange rate nexus in Sierra Leone can better be modeled by the EGARCH $(1,1)$ model. The empirical result suggests that the conditional variance or volatility is quite persistent for Leone/US Dollar. In particular, the results show that exchange rate behavior in Sierra Leone de- 
picts an autoregressive behavior, meaning exchange rate variations is significantly influenced by previous information about exchange rate.

The study further revealed that Sierra Leone's Leone/US Dollar exchange rate is significantly influenced by global oil price shocks, as an increase in global oil prices will lead to a depreciation of the Leone/US Dollar exchange rate. In addition, the results of the EGARCH model also show and support asymmetric behavior and that positive shocks imply a higher next period conditional variance than negative shocks of the same magnitude. The main policy implication of this result is that since oil price volatility impact exchange rate dynamics, the monetary authority should consider the impact of global oil price shocks when formulating and implementing economic policies, especially as they relate to exchange rate.

\section{Conflicts of Interest}

The authors declare no conflicts of interest regarding the publication of this paper.

\section{References}

Afees Salisu and Mobolaji (2013). Modeling Returns and Volatility Transmission between Oil Price and US-Nigeria Exchange Rate. Energy Economics, 39, 169-176. https://doi.org/10.1016/j.eneco.2013.05.003

Aloui, R., Aïssa, M. S. B., \& Nguyen, D. K. (2013). Conditional Dependence Structure between Oil Prices and Exchange Rates: A Copula-GARCH Approach. Journal of International Money and Finance, 32, 719-738. https://doi.org/10.1016/j.jimonfin.2012.06.006

Amano, R. A., \& Van Norden, S. (1998a). Oil Prices and the Rise and Fall of the US Real Exchange Rate. Journal of International Money and Finance, 17, 299-316. https://doi.org/10.1016/S0261-5606(98)00004-7

Amano, R. A., \& Van Norden, S. (1998b). Exchange Rates and Oil Prices. Review of International Economics, 6, 683-669. https://doi.org/10.1111/1467-9396.00136

Bal, D. P., \& Rath, B. N. (2015). Nonlinear Causality between Crude Oil Price and Exchange Rate: A Comparative Study of China and India. Energy Economics, 51, 149156. https://doi.org/10.1016/j.eneco.2015.06.013

Basher, S. A., Haug, A. A., \& Sadorsky, P. (2016). The Impact of Oil Shocks on Exchange Rates: A Markov Switching Approach. Energy Economics, 54, 11-23. https://doi.org/10.1016/j.eneco.2015.12.004

Beckmann, J., \& Czudaj, R. (2013). Is There a Homogeneous Causality Pattern between Oil Prices and Currencies of Oil Importers and Exporters? Energy Economics, 40, 665-678. https://doi.org/10.1016/j.eneco.2013.08.007

Beckmann, J., \& Schüssler, R. (2016). Forecasting Exchange Rates under Parameter and Model Uncertainty. Journal of International Money and Finance, 60, 267-288. https://doi.org/10.1016/j.jimonfin.2015.07.001

Bénassy-Quéré, A., Mignon, V., \& Penot, A. (2007). China and the Relationship between the Oil Price and the Dollar. Energy Policy, 35, 5795-5805.

https://doi.org/10.1016/j.enpol.2007.05.035

Bloomberg, S. B., \& Harris, E. S. (1995). The Commodity-Consumer Price Connection: 
Fact or Fable? Economic Policy Review, 21-38.

Buetzer, S., Habib, M. M., \& Stracca, L. (2016). Global Exchange Rate Configurations: Do Oil Shocks Matter? IMF Economic Review, 64, 443-470. https://doi.org/10.1057/imfer.2016.9

Chris Brooks (2008). Introductory Econometrics for Finance (2nd ed., pp. 406-409). Reading: The ICMA Centre, University of Reading.

Dauda Mohammed, J., Afangideh, U., Ogundelend, O. S. (2019). Oil Price and Exchange Rate Nexus-Evidence from Nigeria. https://doi.org/10.5296/ijafr.v9i1.14386

Engle, R. F. (1982). Autoregressive Conditional Heteroskedasticity with Estimates of the Variance of United Kingdom Inflation. Econometrica, 50, 987-1007. https://doi.org/10.2307/1912773

EViews 9 User's Guide II, Unit Root Tests with a Breakpoint (pp. 557-572).

Fratzscher, M., Schneider, D., \& Van Robays, I. (2014). Oil Prices, Exchange Rates and Asset Prices. Working Paper Series No. 1689, Frankfurt: European Central Bank. https://doi.org/10.2139/ssrn.2269027

Ghosh, S. (2011). Examining Crude Oil Price-Exchange Rate Nexus for India during the Period of Extreme Oil Price Volatility. Applied Energy, 88, 1886.

https://doi.org/10.1016/j.apenergy.2010.10.043

Golub, S. (1983). Oil Prices and Exchange Rates. The Economic Journal, 93, 576-593. https://doi.org/10.2307/2232396

Jiranyakul, K. (2015). Oil Price Volatility and Real Effective Exchange Rate: The Case of Thailand. Bangkok: School of Development Economics, National Institute of Development Administration.

Krugman, P. (1983). Oil and the Dollar. In B. Jagdeeps, \& P. Bulfordh (Eds.), Economic Interdependence and Flexible Exchange Rates. Cambridge, MA: MIT Press.

Mishra, S. (2016). Analysis of Volatility Spill over between Oil Price and Exchange Rate in India: GARCH Approach. Bhubaneswar: Department of Business Administration, Utkal University. https://doi.org/10.2139/ssrn.2892670

Narayan, P. K., Narayan, S., \& Prasad, A. (2008). Understanding the Oil Price-Exchange Rate Nexus for the Fiji Islands. Energy Economics, 30, 2686-2696. https://doi.org/10.1016/j.eneco.2008.03.003

Nelson, D. B. (1991). Conditional Heteroskedasticity in Asset Returns: A New Approach. Econometrica, 59, 347-370. https://doi.org/10.2307/2938260

Nikbakht, L. (2010). Oil Prices and Exchange Rates: The Case of OPEC. Business Intelligence Journal, 3, 83-92.

Oluwatomisin, O., Ojeaga, P., \& Agundip, A. (2014). Oil Price and Exchange Rate Volatility in Nigeria. IOSR Journal of Economics and Finance, 5, 2321-5925.

https://doi.org/10.9790/5933-0540109

Perron, P. (1989). The Great Crash, the Oil Price Shock, and the Unit Root Hypothesis. Econometrica, 57, 1361-1401. https://doi.org/10.2307/1913712

Perron, P., \& Vogelsang, T. J. (1992). Non-Stationarity and Level Shifts with an Application to Purchasing Power Parity. Journal of Business \& Economic Statistics, 10, 301320. https://doi.org/10.1080/07350015.1992.10509907

Reboredo, J. C. (2012). Modelling Oil Price and Exchange Rate Co-Movements. Journal of Policy Modeling, 34, 419-440. https://doi.org/10.1016/j.jpolmod.2011.10.005

Reboredo, J., \& Rivera-Castro, M. A. (2013). A Wavelet Decomposition Approach to Crude Oil Price and Exchange Rate Dependence. Economic Modelling, 32, 42-57. 
https://doi.org/10.1016/j.econmod.2012.12.028

Sibanda, K., \& Mlambo, C. (2014). The Impact of Oil Prices on the Exchange Rate in South Africa. Journal of Economics, 5, 193-199. https://doi.org/10.1080/09765239.2014.11884996

Thorlie, M. A., Song, L. X., Wang, X. G., \& Amin, M. (2014). Modelling Exchange Rate Volatility Using Asymmetric GARCH Models (Evidence from Sierra Leone). International Journal of Science and Research (IJSR), 3, 1206-1214.

https://www.ijsr.net/search index results paperid.php?id=OCT141143

Tiwari, A. K., Mutascu, M. L., \& Albulescu, C. T. (2013). The Influence of the International Oil Prices on the Real Effective Exchange Rate in Romania in a Wavelet Transform Network. Energy Economics, 40, 714-733.

https://doi.org/10.1016/j.eneco.2013.08.016

Turhan, M. I., Sensoy, A., \& Hacihasanoglu, E. (2014). A Comparative Analysis of the Dynamic Relationship between Oil Prices and Exchange Rates. Journal of International Financial Markets, Institutions and Money, 32, 397-414.

https://doi.org/10.1016/j.intfin.2014.07.003

Vogelsang, T. J., \& Perron, P. (1998). Additional Test for Unit Root Allowing for a Break in the Trend Function at an Unknown Time. International Economic Review, 39, 1073-1100. https://doi.org/10.2307/2527353

Wilhelmsson (2006). Garch Forecasting Performance under Different Distribution Assumptions. Journal of Forecasting, 25, 561-578. https://doi.org/10.1002/for.1009

Zhang, Y.-J. (2013). The Links between the Price of Oil and the Value of US Dollar. International Journal of Energy Economics and Policy, 3, 341-351. 